\title{
A review of nebulized drug delivery in COPD
}

This article was published in the following Dove Press journal:

International Journal of COPD

18 October 2016

Number of times this article has been viewed

\section{Donald P Tashkin}

Department of Medicine, David Geffen School of Medicine at UCLA, Los Angeles, CA, USA
Correspondence: Donald P Tashkin Department of Medicine, David Geffen School of Medicine at UCLA, 10833 Le Conte Avenue, Los Angeles, CA 90095, USA

$\mathrm{Tel}+\mathrm{I} 3108253163$

Fax + I 3102065088

Email dtashkin@mednet.ucla.edu
Abstract: Current guidelines recommend inhaled pharmacologic therapy as the preferred route of administration for treating COPD. Bronchodilators ( $\beta_{2}$-agonists and antimuscarinics) are the mainstay of pharmacologic therapy in patients with COPD, with long-acting agents recommended for patients with moderate to severe symptoms or those who are at a higher risk for COPD exacerbations. Dry powder inhalers and pressurized metered dose inhalers are the most commonly used drug delivery devices, but they may be inadequate in various clinical scenarios (eg, the elderly, the cognitively impaired, and hospitalized patients). As more drugs become available in solution formulations, patients with COPD and their caregivers are becoming increasingly satisfied with nebulized drug delivery, which provides benefits similar to drugs delivered by handheld inhalers in both symptom relief and improved quality of life. This article reviews recent innovations in nebulized drug delivery and the important role of nebulized therapy in the treatment of COPD.

Keywords: COPD, nebulized drug delivery, pharmacologic therapy

\section{Introduction}

Inhaled pharmacologic therapy is a cornerstone of treatment for patients with COPD. ${ }^{1,2}$ Four commonly prescribed inhalation devices, pressurized metered dose inhalers (pMDIs), dry powder inhalers (DPIs), slow mist inhalers (SMIs), and nebulizers, have similar efficacies in patients with COPD, ${ }^{3-6}$ provided they are used appropriately. Although DPIs and pMDIs are the most commonly used devices ${ }^{7,8}$ and are recommended for long-term treatment in the vast majority of patients, ${ }^{2}$ the Global Initiative for Chronic Obstructive Lung Disease (GOLD) strategy document recommends nebulizers for specific patient populations (eg, patients with very low inspiratory flow rates) in whom nebulizer treatment may provide more benefits than DPIs or MDIs. ${ }^{2}$ Further, GOLD recommends evaluating the benefits of nebulizer treatment symptomatically and continuing treatment as long as similar benefits are not achievable by simpler, cheaper, and more portable alternatives. In addition, both patients and their caregivers are becoming increasingly satisfied with nebulized drug delivery and have reported benefits in symptom relief, ease of use, and improved quality of life when using this system..$^{9,10}$ Moreover, several of the emerging medications for COPD (both marketed and under development) utilize nebulizer technology. This article reviews recent innovations in nebulized drug delivery and the important role of nebulized therapy in the treatment of COPD.

\section{Selection of articles for review}

After dividing the review topic into specific subsections, articles were selected for inclusion based on comprehensive reviews of the literature according to each subsection. A PubMed search (January 1, 1996 to March 15, 2016) was conducted using 
multiple primary topic headers combined with appropriate terms for each section of the article (eg, COPD + nebulizers or COPD + nebulizer therapy). The results of the PubMed search were supplemented by relevant papers identified from reference lists of published articles and the author's knowledge of the literature. Selection of articles for discussion focused on information published within the past 5 years.

\section{COPD}

COPD, a common preventable and treatable disease, is characterized by progressive persistent airflow obstruction that is associated with an enhanced inflammatory response to noxious particles or gases in the lung and airways., ${ }^{211,12}$ COPD represents a global health problem, is ranked as the fourth leading cause of death in the world, and significantly affects patient quality of life., ${ }^{2,13,14}$ The global social and economic burden of COPD is projected to increase, due to aging populations and the continued use of tobacco and exposure to biomass fuels, ${ }^{15,16}$ underscoring the need for more effective management of this disease. While $>12$ million people in the US are known to have COPD, it is estimated that up to 24 million may have impaired lung function and undiagnosed disease. ${ }^{17}$ In 2010, the cost of COPD in the US was projected to be $\sim \$ 49.9$ billion, which included $\sim \$ 20$ billion in indirect costs (eg, loss of work productivity and earnings) and $\$ 30$ billion in direct health care expenditures (eg, prescription medicines and emergency department visits). ${ }^{17,18}$

To reduce symptoms, frequency, and severity of COPD exacerbations and improve health status and exercise tolerance, the GOLD strategy document ${ }^{2}$ recommends that bronchodilators are the cornerstone of pharmacotherapy for COPD in the majority of patients. ${ }^{1,2}$ However, physical and/or cognitive symptoms that are common in some COPD patients (eg, the elderly ${ }^{19,20}$ ) could interfere with the proper administration of inhaled therapies via handheld inhalers, ${ }^{21}$ resulting in insufficient dosing and jeopardizing health outcomes, reducing quality of life, and further adding to the economic burden of COPD. ${ }^{2,22}$ Further, during exacerbations and in recovery, many COPD patients have decreased peak inspiratory flow rate (PIFR) and are unable to use handheld inhalers effectively. In these populations, inhaled therapies administered via nebulizers may offer improved symptom control ${ }^{21,23}$ and quality of life ${ }^{9}$ over non-nebulized bronchodilator therapy.

\section{Pharmacologic therapy}

In general, pharmacologic therapy is part of an integrated treatment approach in patients with COPD that begins with smoking cessation and vaccines (influenza and pneumococcal) for all current smokers and progresses to treatment with inhaled therapy. ${ }^{24}$ Inhaled treatment is tailored to the patient and should be guided by the severity of COPD symptoms, risk of COPD exacerbations, drug availability, and patient response (Table 1). ${ }^{2}$ For patients at low risk of COPD exacerbations with relatively few symptoms (eg, those in GOLD patient category A), ${ }^{2}$ short-acting bronchodilators are available for acute relief of symptoms or for use before physical activities ${ }^{25}$ to prevent the onset of symptoms (a longacting inhaled bronchodilator, as well as theophylline, is recommended as an alternative choice). ${ }^{2}$ For patients with more severe symptoms or who are at a higher risk of COPD exacerbations (eg, those in GOLD patient categories B, C, or D), long-acting bronchodilators are recommended over short-acting bronchodilators for maintenance therapy to improve symptoms, exercise tolerance, and health-related quality of life and reduce the risk of exacerbations. ${ }^{2}$ As a result, long-acting bronchodilators with or without inhaled corticosteroids (ICS) are the first- or second-choice drugs for the majority of patients with COPD. ${ }^{1}$

Although handheld pMDIs or DPIs are effective in most patients with COPD, cognitively impaired and elderly patients

Table I Initial pharmacologic management of COPD*

\begin{tabular}{|c|c|c|c|}
\hline GOLD patient category & First choice & Alternative choice & Other possible treatments \\
\hline A: low risk, less symptoms & $\begin{array}{l}\text { SAMA prn or } \\
\text { SABA prn }\end{array}$ & LAMA or LABA or SABA and SAMA & Theophylline \\
\hline B: low risk, more symptoms & LAMA or LABA & LAMA and LABA & SABA and/or SAMA; theophylline \\
\hline C: high risk, less symptoms & $\begin{array}{l}\text { ICS + LABA or } \\
\text { LAMA }\end{array}$ & $\begin{array}{l}\text { LAMA and LABA or LAMA and PDE-4 inhibitor or LABA } \\
\text { and PDE- } 4 \text { inhibitor }\end{array}$ & SABA and/or SAMA; theophylline \\
\hline D: high risk, more symptoms & $\begin{array}{l}\text { ICS + LABA } \\
\text { and/or LAMA }\end{array}$ & $\begin{array}{l}\text { ICS and LABA and LAMA or ICS and LABA and PDE-4 } \\
\text { inhibitor or LAMA and LABA or LAMA and PDE- } 4 \text { inhibitor }\end{array}$ & $\begin{array}{l}\text { Carbocysteine; SABA and/or } \\
\text { SAMA; theophylline }\end{array}$ \\
\hline
\end{tabular}

Notes: *Medications are not listed in order of preference. \#Medications in this column can be used alone or in combination with other options in the first and second columns. Reprinted with permission of the American Thoracic Society. Copyright @ 2016 . Vestbo J, Hurd SS, Agusti AG, et al. 20I3. Global strategy for the diagnosis, management, and prevention of chronic obstructive pulmonary disease: GOLD executive summary. Am J Respir Crit Care Med. 187(4):347-365. ${ }^{97}$ The American Journal of Respiratory and Critical Care Medicine is an official journal of the American Thoracic Society.

Abbreviations: GOLD, Global Initiative for Chronic Obstructive Lung Disease; ICS, inhaled corticosteroid; LABA, long-acting $\beta_{2}$-agonist; LAMA, long-acting muscarinic antagonist; PDE-4, phosphodiesterase-4; prn, as needed; SABA, short-acting $\beta_{2}$-agonist; SAMA, short-acting muscarinic antagonist. 
may benefit more from the use of a nebulizer, since these patient populations may have difficulty synchronizing inhalation with inhaler actuation or may be unable to generate a sufficient inspiratory flow rate against the resistance of a breath-activated DPI to generate an effective aerosol. ${ }^{6,22,26-28}$ SMIs are compact portable multidose inhalers that use liquid formulations similar to those in nebulizers but, like MDIs and DPIs, require manual manipulation to generate the aerosol and special breathing techniques for effective delivery of the aerosolized medication to the lungs. ${ }^{29}$ The choice of therapy, however, ultimately depends on a wide range of factors, including the prescribing physician, the availability of specific drug/device pairings, drug cost, and patient preferences and satisfaction. ${ }^{3,22,26,28,30,31}$ Each of the delivery devices that are available for administering drugs to patients with COPD (eg, pMDIs, DPIs, SMIs, and nebulizers) has advantages and disadvantages (Table 2). ${ }^{3,6,29,31,32}$

\section{Nebulized drug delivery}

In patients with COPD, nebulizers are an alternative to pMDIs and DPIs for providing inhaled therapy, provided the drug is available and chemically stable in liquid form (Figure 1). ${ }^{6,31}$ Despite some drawbacks associated with nebulizers (eg, variably long treatment times and daily cleaning), current evidence suggests that the efficacy of treatments administered to patients with moderate to severe COPD via nebulizers is similar to that observed with pMDIs and DPIs. ${ }^{3-6}$ Further, market analysis indicates that, in the US, $\sim 45 \%$ of patients with COPD have a nebulizer, $69 \%$ of whom use it on a regular basis. ${ }^{6}$

Several options exist for the type of nebulizer (eg, jet, ultrasonic, and vibrating mesh), with many models commercially available (Figure 1). The Akita $^{\circledR}$ (Vectura, Chippenham, UK) jet nebulizer individualizes aerosol delivery using the

Table 2 Advantages and disadvantages of aerosolized formulations

\begin{tabular}{|c|c|c|}
\hline Inhalation device & Advantages & Disadvantages \\
\hline \multirow[t]{6}{*}{ DPI } & Breath-actuated devices & Requires patient to generate moderate to high inspiratory flow ${ }^{a}$ \\
\hline & Convenient & Elderly patients and those with hyperinflation and flattened diaphragms \\
\hline & Portable & may have difficulty achieving adequate inspiratory flow \\
\hline & Rapid medication delivery & \\
\hline & Single- and multidose devices & Can result in high pharyngeal and central airway deposition, which can lead \\
\hline & Counter indicates remaining doses & to adverse events \\
\hline \multirow[t]{6}{*}{ pMDI } & Multiple dosing ( $\geq 100$ doses/canister) & Multiple steps involved \\
\hline & & Requires adequate patient coordination to synchronize inhalation with \\
\hline & & pMDI actuation ${ }^{b}$ \\
\hline & Short administration time & High pharyngeal deposition, which can lead to adverse events \\
\hline & Convenient & Only $10 \%-20 \%$ of dose deposited in lungs from suspension MDls ${ }^{c}$ \\
\hline & Portable & $\begin{array}{l}\text { While the addition of spacer eliminates the need to coordinate inhalation } \\
\text { and reduces oropharyngeal deposition, spacers are bulky and require } \\
\text { cleaning }\end{array}$ \\
\hline \multirow[t]{7}{*}{ SMI } & Multiple dosing (I month's supply) & Multiple steps involved \\
\hline & High lung deposition & Not breath actuated \\
\hline & Portable & Not available in most countries \\
\hline & No propellants & \\
\hline & Slow-velocity aerosol generated & \\
\hline & Aerosol persists for 1.5 seconds, increasing & \\
\hline & ease of synchronizing inhalation with actuation & \\
\hline \multirow[t]{6}{*}{ Jet nebulizer } & Easy for patients to use & Limited portability \\
\hline & Requires minimal cognitive ability & Device preparation required \\
\hline & Does not require hand-breath coordination, & Lengthy administration time \\
\hline & manual dexterity, or hand strength & Daily cleaning required \\
\hline & & Not all medications are available in this format \\
\hline & & May not readily aerosolize drug suspensions \\
\hline High-efficiency & Portable & High cost \\
\hline vibrating mesh & Quiet & Device preparation required \\
\hline \multirow[t]{4}{*}{ nebulizer } & Short administration times & Daily cleaning required \\
\hline & & Not all medications are available in this format \\
\hline & & May not readily aerosolize drug suspensions \\
\hline & & Optimal doses need to be defined by additional studies to avoid overdosing \\
\hline
\end{tabular}

Notes: aNot all DPls are high-resistance inhalers, but even the low-resistance inhalers (eg, Breezhaler ${ }^{\circledR}$; Novartis, Basel, Switzerland), require a relatively high inspiratory flow compared with higher resistance devices to generate a comparable pressure drop across the resistance of the device in order to de-agglomerate the powder and generate an effective aerosol. ${ }^{98}$ bBeath-actuated MDIs address this concern and are available in some countries. ${ }^{\text {cHigher }}(\sim 50 \%)$ deposition occurs with solution HFA MDIs (eg, beclomethasone HFA and flunisolide HFA).

Abbreviations: DPI, dry powder inhaler; HFA, hydrofluoroalkane; MDI, metered dose inhaler; pMDI, pressurized metered dose inhaler; SMI, slow mist inhaler. 


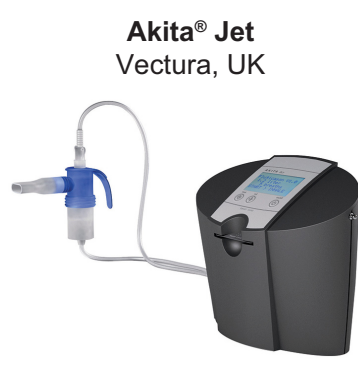

Akita $^{\circledR}$ Jet

eFlow $^{\circledR}$

PARI, USA

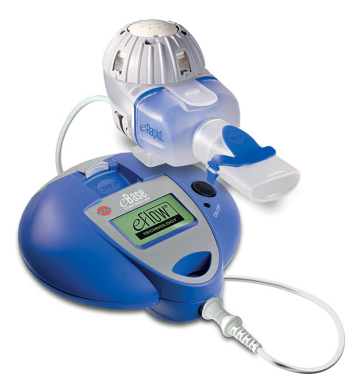

Trek $^{\circledR} \mathbf{S}$

PARI, USA

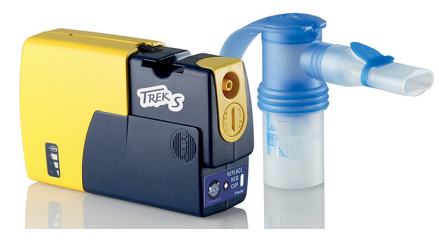

Respimat $^{\circledR}$

Boehringer Ingelheim, Germany

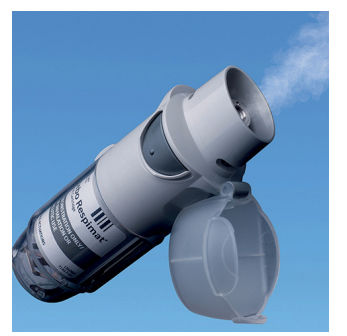

I-neb ${ }^{\circledR}$

Philips Healthcare, USA

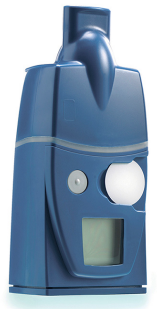

Aeroneb $^{\circledR}$ GO

Philips Healthcare, USA
MicroAir ${ }^{\circledR}$

Omron, USA

Figure I Examples of commercially available nebulizers that incorporate newer aerosol generating technologies.

Notes: Akita ${ }^{\circledR}$ Jet (Courtesy of Ventura, UK) and the I-neb ${ }^{\circledR}$ (Courtesy of Philips Healthcare, USA) employ AAD technology to deliver and monitor nebulizer treatments. Trek ${ }^{\circledR}$ $\mathrm{S}$ (Courtesy of PARI, USA; Trek ${ }^{\circledR} \mathrm{S}$ is a trademark of PARI Gmbh and its affiliates) is a portable jet nebulizer. MicroAir ${ }^{\circledR}$ NE-U22 (Courtesy of Omron, USA) and the eFlow ${ }^{\circledR}$ (Courtesy of PARI, USA; eFlow ${ }^{\circledR}$ is a trademark of PARI Gmbh and its affiliates) are vibrating mesh aerosol nebulizers. Respimat ${ }^{\circledR}$ is a high-efficiency soft mist inhaler (Reproduced with permission from Boehringer Ingelheim Pharmaceuticals, Inc. Respimat ${ }^{\circledR}$ is a trademark of and/or used under license from Boehringer Ingelheim International GmbH or its affiliated companies. Materials may also be subject to copyright protection). Aeroneb ${ }^{\circledR}$ Go (Courtesy of Philips Healthcare) is an ultrasonic nebulizer. All of these devices are approved for use in the US.

Abbreviation: AAD, adaptive aerosol delivery.

adaptive aerosol delivery (AAD) control system (Figure 2), ${ }^{33}$ which results in high efficiency and low variability in aerosol drug delivery to patients. Despite these benefits, however, the Akita, in common with older jet nebulizers, is a large, poorly portable nebulizer that has a longer (10 minutes) treatment time than the newer vibrating mesh nebulizers. ${ }^{34}$ The $^{\text {Trek }}{ }^{\circledR}$
S (PARI, Midlothian, VA, USA) portable jet nebulizer is a convenient alternative to larger, more powerful tabletop compressors. In a comparative study of four portable nebulizer systems, the Trek S delivered 33\% more respirable dose than the next best system, Mini Elite ${ }^{\mathrm{TM}}$ (Philips Healthcare, Andover, MA, USA). ${ }^{35}$

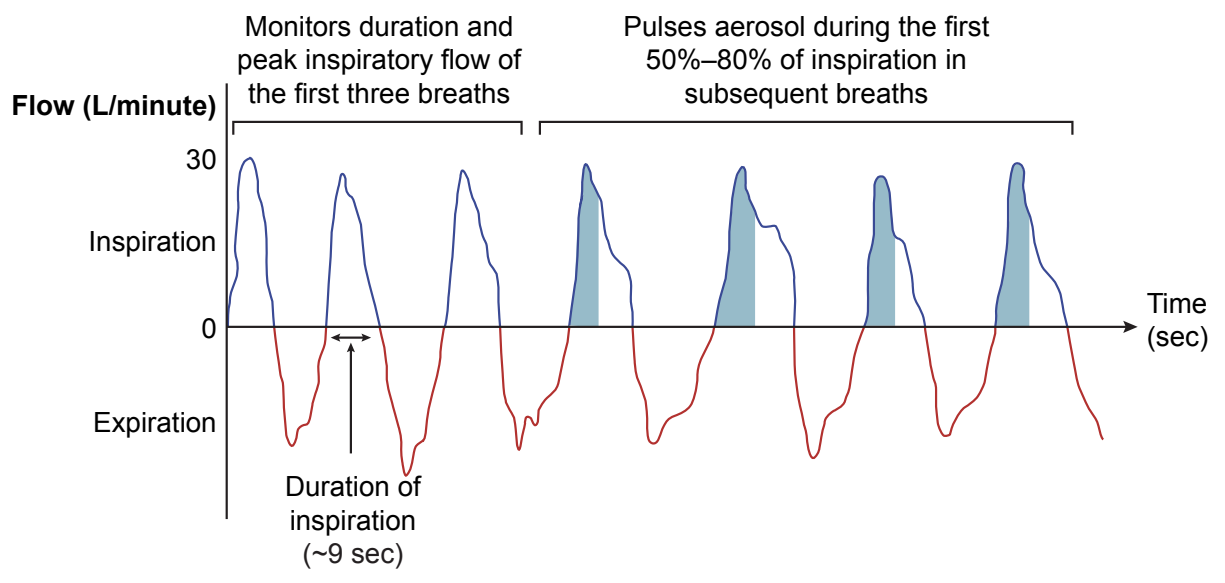

Figure 2 AAD technology used in the Akita ${ }^{\circledR}$ and I-neb ${ }^{\circledR}$ nebulizers.

Notes: During the first three breaths, AAD calculates when to pulse the aerosol. In subsequent breaths, AAD pulses aerosol during the first $50 \%-80 \%$ of inspiration (blue shade). Republished with permission of Respiratory Care: the official science journal of the American Association for Respiratory Care, from New Aerosol Delivery Devices for Cystic Fibrosis, KC Kesser and DE Geller, volume 54, edition 6, 2009; permission conveyed through Copyright Clearance Center, Inc. ${ }^{105}$

Abbreviation: AAD, adaptive aerosol delivery. 
The Aeroneb ${ }^{\circledR}$ Go (Philips Healthcare) is a portable, compact, handheld ultrasonic nebulizer that is easily assembled, silent, and has short (5 minutes) treatment duration. ${ }^{3,6,34}$ The eFlow ${ }^{\circledR}$ (PARI) is a battery-operated, compact, portable vibrating mesh nebulizer that has been shown to improve patient compliance due to its comparatively short (5 minutes) treatment time. ${ }^{36}$ MicroAir ${ }^{18}$ NE-U22 (Omron, Chicago, IL, USA) is a mesh nebulizer that provides efficient aerosol drug delivery with a predominantly fine particle fraction. ${ }^{3,6,34}$ Like the Aeroneb Go and eFlow devices, the MicroAir is expensive and can be difficult to maintain, as it requires disassembly and cleaning after each use to prevent clogging of the mesh apertures. ${ }^{34}$

The I-neb ${ }^{\circledR}$ (Philips Healthcare) AAD nebulizer is a small, lightweight, battery-powered, silent smart nebulizer that combines mesh and AAD technologies to deliver a precise, reproducible dose. ${ }^{6,34}$ With AAD technology, automated timing of aerosol delivery (based on the patient's breathing pattern) improves the precision and reproducibility of dosing ${ }^{34}$ (Figure 2) and, compared with previous nebulizers without $\mathrm{AAD}$, significantly improves dyspnea and fatigue in patients with COPD. ${ }^{37} \mathrm{~A}$ disadvantage of the newer mesh nebulizers is that little information is available concerning the ideal dose of the bronchodilator solution to add to the nebulizer. Consequently, the potential for overdosing exists if the same dose of the bronchodilator that is conventionally used with jet nebulizers is added to these newer nebulizers. To address this concern, device manufacturers are developing a new generation of closed-system mesh nebulizers that will accept only the ampule containing the specific drug approved for use with a specific device based on the demonstration of safety and efficacy. ${ }^{31}$

The Respimat ${ }^{\circledR}$ (Boehringer Ingelheim, Ingelheim, Germany) is an SMI that delivers a slow-moving mist, allowing the inhalation of medication independent of inspiratory effort ${ }^{38}$ (ie, via the release of stored energy from a tensed spring when the tension is released by pushing a button). Although not strictly classified as a nebulizer, the Respimat device, a compact handheld aerosol delivery device similar in size to MDIs and DPIs, is included here because it shares several performance characteristics with the nebulizers discussed earlier, such as liquid formulation, propellant-free function, use of mechanical energy for actuation, generation of an aerosol with a predominantly fine particle fraction (micronebulized), and lack of dependence on high inspiratory flow rates. ${ }^{38}$ However, in contrast to more conventional nebulizers for which only tidal breathing is required, use of the Respimat requires a special breathing technique (full expiration followed by full inhalation and breath holding). ${ }^{38}$ Some coordination between inhalation and actuation is also necessary, although the timing for such is more forgiving with the Respimat than for MDI devices, since the aerosol delivered from the Respimat lasts 1.5 seconds (as opposed to a fraction of a second from an MDI).

\section{Nebulized pharmacologic therapy}

Many of the drugs used for the treatment of COPD were initially approved for use in pMDIs or DPIs ${ }^{39}$ and are now available in solution form for use with nebulizers (Table 3 ). The long-acting agents are indicated for maintenance treatment of COPD-associated airflow obstruction, while short-acting bronchodilators are indicated for acute relief of bronchospastic symptoms of COPD. Clinical trials generally have demonstrated significant improvement in forced expiratory volume in 1 second $\left(\mathrm{FEV}_{1}\right)$ over the dosing interval and reduction in rescue medication use with nebulized therapy.

\section{Long-acting $\beta_{2}$-agonists (LABAs) Arformoterol}

Nebulized arformoterol tartrate is of potential benefit to patients with hyperinflation and low PIFR. ${ }^{40}$ Arformoterol is safe in combination therapy with certain handheld inhalers (eg, ICS, long-acting muscarinic antagonists [LAMAs], and short-acting $\beta_{2}$-agonists [SABAs]), but it is contraindicated in combination with a handheld inhaled LABA (alone or in combination with an ICS or an LAMA). A 12-month Phase 4 trial found no increased risk of respiratory death or COPD exacerbation-related hospitalizations with nebulized arformoterol treatment. ${ }^{41}$ Being a single enantiomer of formoterol, arformoterol may have hypothetically more potent bronchodilator properties, microgram per microgram, than racemic formoterol fumarate, but no major clinical differences between the two drugs have been observed in patients with COPD ${ }^{42}$ Maintenance therapy with nebulized arformoterol or formoterol demonstrated a $37 \%$ reduction and a $42 \%$ reduction in rescue albuterol use, respectively. ${ }^{43,44}$ Partial tolerance to the bronchodilator effect of arformoterol was noted after 6 weeks of therapy, but the reduction in bronchodilator efficacy did not progress beyond 6 weeks and was not considered clinically significant ${ }^{44}$ Finally, arformoterol can improve lung function in combination with LAMAs. In patients with COPD who were receiving twice-daily nebulized arformoterol, tiotropium bromide given in combination with arformoterol produced significantly greater bronchodilation than either arformoterol or tiotropium monotherapies $(P<0.001){ }^{45}$

\section{Formoterol}

Formoterol differentiates from some other $\beta_{2}$-agonists by its rapid onset of significant bronchodilation within 5 minutes of administration..$^{46,47}$ In patients with COPD, nebulized 
Table 3 Nebulized medications commonly used for patients with COPD

\begin{tabular}{|c|c|c|c|c|}
\hline Compound & $\begin{array}{l}\text { Nebulizer } \\
\text { system }\end{array}$ & $\begin{array}{l}\text { Trough FEV (L) } \\
\text { improvement* }\end{array}$ & $\begin{array}{l}\text { Rescue medication } \\
\text { use reduction }\end{array}$ & Remarks \\
\hline \multicolumn{5}{|l|}{ LABA $^{\#}$} \\
\hline Arformoterol tartrate ${ }^{40}$ & Jet or VM & $0.051^{\pi}$ & Yes & BID; less frequent exacerbations of COPD than placebo \\
\hline Formoterol fumarate ${ }^{99}$ & Jet or VM & $0.143^{\pi}$ & Yes & BID; no tachyphylaxis during 12 weeks of regular dosing \\
\hline Olodaterol hydrochloride $e^{100}$ & $\mathrm{SMI}^{\dagger}$ & $0.275^{* *}$ & Yes & QD \\
\hline \multicolumn{5}{|l|}{ LAMA $^{\#}$} \\
\hline Tiotropium bromide ${ }^{101}$ & SMI & $0.232^{* *}$ & Yes & QD; noninferior to tiotropium 18 mg HandiHaler ${ }^{\circledR}$ \\
\hline \multicolumn{5}{|l|}{ LABA-LAMA ${ }^{\#}$} \\
\hline $\begin{array}{l}\text { Tiotropium bromide- } \\
\text { olodaterol hydrochloride }{ }^{62}\end{array}$ & SMI & $0.068^{\prime \prime}$ & Yes & $\begin{array}{l}\text { QD; additive bronchodilation without increasing side } \\
\text { effects; less rescue medication vs components alone }\end{array}$ \\
\hline \multicolumn{5}{|l|}{$\mathrm{SABA}^{\ddagger}$} \\
\hline Albuterol sulfate ${ }^{102}$ & Jet or VM & NR & NA & $\begin{array}{l}\text { prn rescue drug; requires } 2-4 \text { daily doses if used as } \\
\text { maintenance treatment }\end{array}$ \\
\hline Levalbuterol hydrochloride ${ }^{103}$ & Jet or VM & NR & NA & prn rescue drug \\
\hline \multicolumn{5}{|c|}{ SAMA $^{\ddagger}$} \\
\hline Ipratropium bromide ${ }^{68}$ & Jet or VM & NR & NA & $\begin{array}{l}\text { Indicated as a bronchodilator for maintenance } \\
\text { treatment of bronchospasm associated with COPD }\end{array}$ \\
\hline \multicolumn{5}{|l|}{ SABA-SAMA' } \\
\hline Albuterol-ipratropium ${ }^{69}$ & Jet or VM & NR & NA & Improved FEV, response vs components alone \\
\hline Albuterol-ipratropium ${ }^{70}$ & SMI & NR & NA & $\begin{array}{l}\text { Provides better bronchodilation than either therapy } \\
\text { alone without increasing side effects }\end{array}$ \\
\hline
\end{tabular}

Notes: *Treatment differences (vs placebo) in trough FEV, change from baseline. \#Indicated for long-term, maintenance treatment of bronchospasm. ${ }^{\ddagger}$ Indicated for the treatment of acute exacerbations. Indicated for the treatment of acute exacerbations in patients requiring more than one bronchodilator. ${ }^{\top} P<0.05$; $* * P<0.000 \mathrm{I}$ vs placebo. tSoft mist inhaler (Respimat ${ }^{\circledR}$ ) is not a nebulizer, but has some similar performance characteristics. "P $<0.05$ vs single agents used alone.

Abbreviations: BID, twice daily; FEV , forced expiratory volume in I second; LABA, long-acting $\beta_{2}$-agonist; LAMA, long-acting muscarinic antagonist; NA, not applicable; NR, not reported; prn, as needed; QD, once daily; SABA, short-acting $\beta_{2}$-agonist; SAMA, short-acting muscarinic antagonist; SMI, soft mist inhaler; VM, vibrating mesh.

formoterol fumarate significantly increased $\mathrm{FEV}_{1}$ relative to placebo $(P<0.001)$ when administered for 12 weeks and had similar efficacy and safety compared with the original formoterol fumarate dry powder formulation. ${ }^{46}$ Quality of life at week 12, as measured by the St George's Respiratory Questionnaire, demonstrated significant and clinically meaningful improvements in total score, symptom, and impact scores for formoterol vs placebo. Patients treated with formoterol reported greater treatment satisfaction and perception of disease control compared with treatment with short-acting bronchodilators delivered 4 times daily. ${ }^{48}$ Furthermore, similar to arformoterol, ${ }^{45}$ nebulized formoterol significantly increased bronchodilation in patients receiving the LAMA tiotropium bromide, ${ }^{49}$ which indicates that formoterol can improve lung function in combination with antimuscarinics. With regard to tachyphylaxis to the bronchodilator effect of formoterol + tiotropium, tachyphylaxis was not observed during 6 weeks of formoterol add-on treatment in patients receiving tiotropium maintenance therapy, ${ }^{50,51}$ which is consistent with 12-week trials that did not show any tolerance to the effect of formoterol alone in patients with COPD. ${ }^{46}$

\section{Olodaterol SMI}

Olodaterol hydrochloride SMI is a long-term, once-daily maintenance treatment for controlling symptoms in adults with COPD..$^{52,53}$ In Phase 3 trials, once-daily olodaterol improved lung function $\left(\mathrm{FEV}_{1}\right)$ compared with placebo over 48 weeks of treatment, with bronchodilation being achieved and maintained within the 24-hour dosage interval, supporting its once-daily administration. ${ }^{52,54}$ Olodaterol SMI is not indicated to treat either acute deterioration of COPD or asthma.

\section{LAMA}

\section{Tiotropium SMI}

Tiotropium bromide SMI provides a solution form of tiotropium bromide ${ }^{55}$ that is efficacious at lower doses compared with the tiotropium bromide HandiHaler ${ }^{\circledR}$ (Boehringer Ingelheim). ${ }^{56}$ In patients with COPD, tiotropium SMI improved lung function, health-related quality of life, and dyspnea, reduced acute exacerbations of COPD, and was as effective and safe as the tiotropium HandiHaler ${ }^{57,58}$ Tiotropium is generally well tolerated in patients with COPD, but antimuscarinic side effects (eg, dry mouth) are among the most commonly reported adverse events. ${ }^{59}$

\section{LABA-LAMA fixed-dose combination Tiotropium-olodaterol SMI}

Tiotropium bromide-olodaterol hydrochloride SMI, a fixeddose combination daily maintenance treatment for patients 
with COPD ${ }^{60,61}$ has demonstrated superior efficacy compared with the individual LABA and LAMA components alone. ${ }^{62}$ Two replicate 52-week trials showed significantly greater improvement in $\mathrm{FEV}_{1}$ area under the curve (AUC) from time 0 to 3 hours, trough $\mathrm{FEV}_{1}$, quality of life (as measured by the St George's Respiratory Questionnaire), and dyspnea with tiotropium-olodaterol SMI compared with the individual components delivered by SMI. ${ }^{62}$ Moreover, in a placebo-controlled trial, tiotropium-olodaterol SMI has been shown to result in a clinically meaningful improvement in quality of life compared with placebo. ${ }^{63}$

\section{SABA}

Nebulized albuterol sulfate and levalbuterol hydrochloride are short-acting medications commonly used to treat acute episodes of bronchospasm and acute exacerbations in patients with COPD. ${ }^{64,65}$ Randomized, controlled clinical studies generally have not demonstrated any significant differences between levalbuterol and albuterol in efficacy, occurrence of adverse effects, or hospital admissions. ${ }^{66}$ Levalbuterol may have advantages over albuterol in patients with COPD admitted to the hospital, including shorter (1 day) length of stay, ${ }^{67}$ but albuterol was found to be 3 -fold less expensive than levalbuterol in a 2009 study. ${ }^{66}$

\section{Short-acting muscarinic antagonist (SAMA)}

Ipratropium

Ipratropium bromide, an SAMA in a nebulized inhalation solution administered either alone or with other bronchodilators (eg, $\beta_{2}$-agonists), is indicated as a bronchodilator for the maintenance treatment of bronchospasm associated with COPD, including chronic bronchitis and emphysema, when administered on a regularly scheduled four times daily schedule.$^{68}$ In 12 -week clinical studies in patients with COPDassociated bronchospasm associated with COPD, significant improvements in pulmonary function ( $\mathrm{FEV}_{1}$ increases of $15 \%$ or more) occurred within 15-30 minutes and persisted for periods of 4-5 hours in the majority of patients.

\section{SABA-SAMA fixed-dose combination}

\section{Albuterol-ipratropium}

Nebulized albuterol sulfate-ipratropium bromide, a fixeddose combination product, is indicated for the treatment of bronchospasm associated with COPD in patients requiring more than one bronchodilator. ${ }^{69,70}$ Research has shown that patients with COPD treated with albuterol-ipratropium have lower hospital expenditures and therapy interruptions than patients taking the individual components as dual single agents (DSAs). ${ }^{71}$ In a population-based retrospective claims analysis, patients who were taking nebulized albuterol-ipratropium $(n=468)$ had 31\% fewer emergency department visits and costs compared with patients taking a DSA ( $P=0.03$ and $P<0.001$, respectively). In addition, the albuterol-ipratropium cohort was associated with statistically fewer individuals who reported treatment interruptions $(10 \% ; P=0.003)$.

\section{Albuterol-ipratropium SMI}

Albuterol sulfate-ipratropium bromide SMI is indicated for patients with COPD on a regular aerosol bronchodilator who continue to have evidence of bronchospasm and who require a second bronchodilator. ${ }^{72}$ In a controlled clinical study, 652 patients with moderate to severe COPD received either albuterol, ipratropium, or albuterol-ipratropium SMI for 85 days. $^{70}$ Over the course of the study, the acute pulmonary function response (peak expiratory flow rate) was significantly better with albuterol-ipratropium compared with albuterol or ipratropium alone; quality of life and symptoms, however, were unchanged over the course of the study in all treatment groups. The use of an SAMA either as a single agent (eg, ipratropium) or in combination with a short-acting $\beta$-agonist (eg, albuterol) is not recommended in patients receiving concomitant therapy with an LAMA because of concern regarding possible additive anticholinergic side effects and, hypothetically, displacement of the more effective long-acting agent by the short-acting drug from the muscarinic receptor.

\section{Nebulized therapy in development}

Despite the benefits of combination therapies, the late-stage development pipeline of nebulized medications for the treatment of COPD currently comprises two LAMA monotherapies, SUN-101 (Sunovion, Marlborough, MA, USA) and TD-4208 (Theravance, South San Francisco, CA, USA), that could provide improvements over existing drugs (Table 4).

\section{SUN-I0I}

SUN-101, a soluble glycopyrrolate bromide formulation in Phase 3 development, is rapidly (within 2 minutes) delivered to the lungs using a novel custom-designed, portable electronic nebulizer device (eFlow). SUN-101 is in Phase 3 development as a twice-daily maintenance treatment of bronchoconstriction in patients with COPD, including those with chronic bronchitis and emphysema. In controlled Phase 2 studies, SUN-101 demonstrated the rapid onset ( $\leq 5$ minutes) of dose-related bronchodilation following single-dose administration $(12.5-400 \mu \mathrm{g})$ in patients with moderate to 
Table 4 Nebulized therapies in clinical development for the treatment of COPD

\begin{tabular}{|c|c|c|c|c|c|}
\hline $\begin{array}{l}\text { Development } \\
\text { compound }\end{array}$ & Chemical name & $\begin{array}{l}\text { Nebulizer } \\
\text { system }\end{array}$ & $\begin{array}{l}\text { Trough FEV }(\mathrm{L}) \\
\text { improvement* }\end{array}$ & $\begin{array}{l}\text { Rescue medication } \\
\text { use reduction }\end{array}$ & $\begin{array}{l}\text { Stage of } \\
\text { development }\end{array}$ \\
\hline \multicolumn{6}{|l|}{ LAMA $^{\#}$} \\
\hline SUN-I0I & Glycopyrrolate bromide & eFlow $^{\circledR \ddagger}$ & $0.1184^{1,73}$ & NR & Phase $3^{75-77}$ \\
\hline TD-4208 & $\begin{array}{l}\text { Revefenacin (proposed international } \\
\text { nonproprietary name) }\end{array}$ & Jet or VM & $0.187^{1,104}$ & Yes & Phase $3^{83-85}$ \\
\hline
\end{tabular}

Notes: *Treatment differences (vs placebo) in trough FEV, change from baseline. \#Long-term, maintenance treatment of bronchospasm. ${ }^{\star} \mathrm{eFlow}{ }^{\circledR}$ utilizes a vibrating mesh aerosol generator. $P<0.001$.

Abbreviations: $\mathrm{FEV}_{1}$, forced expiratory volume in I second; LAMA, long-acting muscarinic antagonist; NR, not reported; VM, vibrating mesh.

severe COPD. ${ }^{73}$ SUN-101 produced clinically meaningful improvements in lung function $\left(\mathrm{FEV}_{1}\right)$ that were maintained over a 24 -hour period at all doses $>50 \mu$ g. Phase 2 clinical studies also demonstrated that SUN-101 has a safety profile similar to tiotropium, ${ }^{74}$ with no clinically relevant changes in heart rate, systolic and diastolic blood pressure, or in electrocardiographic parameters including QTc interval. ${ }^{73}$ The SUN-101 Phase 3 program consists of three clinical trials that will enroll $\sim 2,340$ adults with moderate to very severe COPD. ${ }^{75-77}$

\section{Revefenacin (TD-4208)}

Revefenacin is a nebulized LAMA with similar potency to tiotropium bromide but with less potential for antimuscarinic side effects (eg, dry mouth). ${ }^{78,79}$ Revefenacin, administered via the PARI Trek $\mathrm{S}$ nebulizer, is in clinical development as a once-daily maintenance treatment for COPD. The results of several Phase 2 studies support the ongoing Phase 3 program. Evaluation of the pharmacokinetics of revefenacin $(n=127)$ demonstrated low plasma concentrations after inhaled administration, consistent with high systemic clearance and a lack of systemic antimuscarinic activity. ${ }^{80} \mathrm{~A}$ randomized, crossover, 7-day, multiple-dose study demonstrated that the bronchodilator effect of once-daily revefenacin was sustained for more than 24 hours in patients with COPD. ${ }^{81}$ In a 28-day dose-ranging Phase 2 study in patients with COPD, revefenacin-treated patients' use of rescue medication was significantly reduced by more than one puff per day in a dose-dependent manner $(P<0.01){ }^{82}$ The Phase 3 program consists of three clinical trials that will enroll $>2,000$ patients with moderate to very severe $\mathrm{COPD}^{83-85}$ and is designed to support regulatory approval of the drug in the US.

\section{Discussion}

With patients becoming increasingly satisfied with nebulized drug delivery, ${ }^{9}$ improved integration of nebulizers and nebulized therapies into the COPD treatment paradigm should lead to improved clinical and health economic outcomes for patients with COPD. Certain COPD patient populations may especially benefit from the use of nebulizer therapy (eg, patients with low PIFR, the elderly, and those with cognitive or visual impairment or diminished manual dexterity). It is therefore important to select the appropriate device for each patient, particularly in older or more severely impacted patients who may be unable to use handheld devices reliably or those who prefer the feeling of control with a nebulized product. ${ }^{48}$

Many emerging COPD medications employ portable nebulizers that are typically battery operated, making them less cumbersome to carry. Compared with pMDIs and DPIs, these nebulizers require no hand-breath coordination or extra effort during inhalation. ${ }^{6}$ Further, the wider availability of high-efficiency nebulizers will ensure accurate delivery of emerging nebulized medications in patients with COPD, which may lead to further reductions in symptoms and exacerbation rates in these patients. However, safety and efficacy studies will be required to define the optimal doses of medications using these high-efficiency nebulizers. Moreover, patient education is crucially important to foster adherence to regular use of nebulized long-acting bronchodilators as part of maintenance therapy, rather than relying on short-acting nebulized agents that should be reserved for rescue treatment of acute symptoms.

When evaluating a nebulized drug delivery option for patients with COPD, important considerations include the availability of specific drug/nebulizer pairings, the need for drug combinations, the ability to use the selected device correctly, drug/nebulizer cost and reimbursement, patient preference and satisfaction, and clinical scenario. ${ }^{3,22,26,28,30}$ Nebulized drug delivery is generally preferred by patients discharged from hospitals after an inpatient stay, who have demonstrated consistent difficulty using handheld inhalers, and who have impaired manual dexterity, impaired cognition, or chronic muscle weakness. ${ }^{6}$ In these scenarios, the benefits of nebulization therapy can outweigh potential inconveniences and lead to improved adherence and 
outcomes in patients with COPD. ${ }^{9}$ For some patients, use of both a nebulizer (as maintenance therapy) and a handheld inhaler (as rescue medication, particularly when outside the home) may provide the best combination of efficacy and convenience. ${ }^{6,26,86}$

Long-acting agents formoterol fumarate and arformoterol tartrate, which currently serve as the mainstays of nebulized maintenance therapy for COPD, have demonstrated a significant reduction in $\mathrm{FEV}_{1}$, but there are no head-to-head clinical trials comparing the efficacy and safety of these two nebulized therapies. While tolerance (tachyphylaxis) to the bronchodilator effect of arformoterol has been reported in clinical trials,${ }^{40,44,87}$ no other clinical manifestations of tolerance were evident. In contrast, clinical trials with nebulized formoterol failed to show any evidence of tolerance, as indicated by maintained $\mathrm{FEV}_{1}$ AUC and reduced rescue inhaler use with up to 12 weeks of treatment. ${ }^{46}$

Combination therapy involving two long-acting bronchodilators with differing mechanisms of action is recommended in patients whose COPD is not well controlled with one drug alone. ${ }^{1,88}$ LABA and LAMA combinations, for example, have shown additive bronchodilator effects at doses used for monotherapy without additional safety concerns ${ }^{89}$ and may increase patient adherence..$^{90}$ Approval of the two nebulized LAMA compounds in Phase 3 clinical trials, SUN-101 and TD-4208, will likely increase the use of combination LABA/LAMA nebulized therapy, although a fixed-dose LABA/LAMA combination nebulized product would also be welcome from a patient compliance perspective. Further, the development of a nebulized version of the widely used fixed-dose combination therapy, ICS/LABA, would benefit patients who need or prefer nebulized treatments.

The recent approval of tiotropium-olodaterol SMI ${ }^{62}$ illustrates that demand for combination therapy is driving device innovation. Cosuspension-based pMDIs, for example, are in development, ${ }^{89,91,92}$ which may facilitate further innovation in fixed-dose combination inhaler products. For example, the US Federal Drug Administration recently approved a novel LAMA/LABA cosuspension-based pMDI (glycopyrrolate and formoterol fumarate) for patients with COPD. ${ }^{93}$ Triple therapy for COPD (ie, treatments containing LABA, LAMA, and ICS) has also been proposed as a convenient treatment option for COPD. ${ }^{94,95}$ Indeed, the first triple inhaler containing formoterol, tiotropium, and ciclesonide is already on the market in India. ${ }^{96}$

Future treatment of patients with COPD will require the continued development of novel nebulizer devices and drugs for patient groups and clinical scenarios where existing
pMDI/DPI therapy is inadequate. Health care providers should stay up to date regarding emerging nebulized treatment options that could provide additional clinical benefits for their patients. In daily practice, prescribing the most appropriate nebulized therapy should take into consideration the available drug formulations, combinations, and devices, as well as the patients' pulmonary function, skills, and preferences. Thus, health care providers and patients together can optimize the benefits of available nebulized treatments for patients with COPD.

\section{Acknowledgments}

Mylan Inc. (Canonsburg, PA, USA) funded medical writing support. Roger J Hill, PhD, of Ashfield Healthcare Communications (Haddam, CT, USA) drafted and revised the manuscript based on the input from the author, and Paula Stuckart of Ashfield Healthcare Communications copyedited and styled the manuscript as per journal requirements.

\section{Disclosure}

The author reports personal fees from Mylan, grants and personal fees from Sunovion, grants and personal fees from Boehringer-Ingelheim, and personal fees from Theravance during the conduct of this study. Outside the conduct of this study, the author reports grants and personal fees from AstraZeneca and personal fees from Novartis.

\section{References}

1. Barjaktarevic IZ, Arredondo AF, Cooper CB. Positioning new pharmacotherapies for COPD. Int J Chron Obstruct Pulmon Dis. 2015; 10:1427-1442.

2. Global Initiative for Chronic Obstructive Lung Disease (GOLD) [webpage on the Internet]. Global Strategy for Diagnosis, Management, and Prevention of COPD - 2016. Available from: http:/goo.gl/ItQL3a. Accessed May 4, 2016.

3. Dolovich MB, Ahrens RC, Hess DR, et al; American College of Chest Physicians; American College of Asthma, Allergy, and Immunology. Device selection and outcomes of aerosol therapy: evidence-based guidelines: American College of Chest Physicians/American College of Asthma, Allergy, and Immunology. Chest. 2005;127(1):335-371.

4. Ram FS, Brocklebank DM, Muers M, Wright J, Jones PW. Pressurised metered-dose inhalers versus all other hand-held inhalers devices to deliver bronchodilators for chronic obstructive pulmonary disease. Cochrane Database Syst Rev. 2002;(1):CD002170.

5. Turner MO, Patel A, Ginsburg S, FitzGerald JM. Bronchodilator delivery in acute airflow obstruction. A meta-analysis. Arch Intern Med. 1997;157(15):1736-1744.

6. Dhand R, Dolovich M, Chipps B, Myers TR, Restrepo R, Farrar JR. The role of nebulized therapy in the management of COPD: evidence and recommendations. COPD. 2012;9(1):58-72.

7. Bonini M, Usmani OS. The importance of inhaler devices in the treatment of COPD. COPD Res Pract. 2015;1(1):1-9.

8. Lavorini F, Corrigan CJ, Barnes PJ, et al; Aerosol Drug Management Improvement Team. Retail sales of inhalation devices in European countries: so much for a global policy. Respir Med. 2011;105(7): 1099-1103. 
9. Sharafkhaneh A, Wolf RA, Goodnight S, Hanania NA, Make BJ, Tashkin DP. Perceptions and attitudes toward the use of nebulized therapy for COPD: patient and caregiver perspectives. COPD. 2013; 10(4):482-492.

10. Barta SK, Crawford A, Roberts CM. Survey of patients' views of domiciliary nebuliser treatment for chronic lung disease. Respir Med. 2002; 96(6):375-381.

11. Qaseem A, Wilt TJ, Weinberger SE, et al; American College of Physicians; American College of Chest Physicians; American Thoracic Society; European Respiratory Society. Diagnosis and management of stable chronic obstructive pulmonary disease: a clinical practice guideline update from the American College of Physicians, American College of Chest Physicians, American Thoracic Society, and European Respiratory Society. Ann Intern Med. 2011;155(3):179-191.

12. Angelis N, Porpodis K, Zarogoulidis P, et al. Airway inflammation in chronic obstructive pulmonary disease. J Thorac Dis. 2014;6(suppl 1): S167-S172.

13. Vos T, Flaxman AD, Naghavi M, et al. Years lived with disability (YLDs) for 1160 sequelae of 289 diseases and injuries 1990-2010: a systematic analysis for the global burden of disease study 2010 . Lancet. 2012;380(9859):2163-2196.

14. Lozano R, Naghavi M, Foreman K, et al. Global and regional mortality from 235 causes of death for 20 age groups in 1990 and 2010: a systematic analysis for the global burden of disease study 2010 . Lancet. 2012;380(9859):2095-2128.

15. Landis SH, Muellerova H, Mannino DM, et al. Continuing to confront COPD international patient survey: methods, COPD prevalence, and disease burden in 2012-2013. Int J Chron Obstruct Pulmon Dis. 2014;9: 597-611.

16. Mannino DM, Buist AS. Global burden of COPD: risk factors, prevalence, and future trends. Lancet. 2007;370(9589):765-773.

17. Lung.org [webpage on the Internet]. American Lung Association. COPD fact sheet [updated 2011]. Available from: http://www.lung. org/lung-disease/copd/resources/facts-figures/COPD-Fact-Sheet.html. Accessed March 3, 2016.

18. Nhlbi.nih.gov [webpage on the Internet]. National Heart Lung and Blood Institute. Morbidity and mortality: 2012 chart book on cardiovascular, lung, and blood diseases. Available from: http://www.nhlbi.nih.gov/ resources/docs/cht-book.htm. Accessed March 3, 2016.

19. Akinbami LJ, Liu X. Chronic obstructive pulmonary disease among adults aged 18 and over in the United States, 1998-2009. NCHS Data Brief. 2011;(63):1-8.

20. CDC.gov. Centers for Disease Control and Prevention. National Center for Health Statistics. Data brief 63: chronic obstructive pulmonary disease among adults aged 18 and over in the United States, 1998-2009. Available from: http://www.cdc.gov/nchs/data/databriefs/db63_tables. pdf\#2. Accessed March 4, 2016.

21. Quinet P, Young CA, Heritier F. The use of dry powder inhaler devices by elderly patients suffering from chronic obstructive pulmonary disease. Ann Phys Rehabil Med. 2010;53(2):69-76.

22. Taffet GE, Donohue JF, Altman PR. Considerations for managing chronic obstructive pulmonary disease in the elderly. Clin Interv Aging. 2014;9:23-30.

23. Mahler DA, Waterman LA, Ward J, Gifford AH. Comparison of dry powder versus nebulized beta-agonist in patients with COPD who have suboptimal peak inspiratory flow rate. J Aerosol Med Pulm Drug Deliv. 2014;27(2):103-109.

24. Celli BR. Update on the management of COPD. Chest. 2008;133(6): 1451-1462.

25. Mayoclinic.org [webpage on the Internet]. Diseases and conditions:

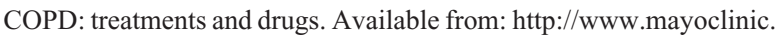
org/diseases-conditions/copd/basics/treatment/con-20032017. Accessed March 18, 2016.

26. Barrons R, Pegram A, Borries A. Inhaler device selection: special considerations in elderly patients with chronic obstructive pulmonary disease. Am J Health Syst Pharm. 2011;68(13):1221-1232.
27. Dekhuijzen PN, Bjermer L, Lavorini F, Ninane V, Molimard M, Haughney J. Guidance on handheld inhalers in asthma and COPD guidelines. Respir Med. 2014;108(5):694-700.

28. Melani AS, Bonavia M, Cilenti V, et al; Gruppo Educazionale Associazione Italiana Pneumologi Ospedalieri. Inhaler mishandling remains common in real life and is associated with reduced disease control. Respir Med. 2011;105(6):930-938.

29. Newman SP. Inhaler treatment options in COPD. Eur Respir Rev. 2005;14(96):102-108.

30. Dolovich MB, Dhand R. Aerosol drug delivery: developments in device design and clinical use. Lancet. 2011;377(9770):1032-1045.

31. Berlinski A. Assessing new technologies in aerosol medicine: strengths and limitations. Respir Care. 2015;60(6):833-847. [discussion 847-849].

32. Rau JL. Practical problems with aerosol therapy in COPD. Respir Care. 2006;51(2):158-172.

33. Rubin BK. Pediatric aerosol therapy: new devices and new drugs. Respir Care. 2011;56(9):1411-1421. [discussion 1421-1423].

34. Ari A. Jet, ultrasonic, and mesh nebulizers: an evaluation of nebulizers for better clinical outcomes. Eurasian J Pulmonol. 2014;16:1-7.

35. Zeman K, Tiffin N. Efficiency of portable jet nebulizer systems using budesonide. Am J Respir Crit Care Med. 2010;181:A1347.

36. Lenney W, Edenborough F, Kho P, Kovarik JM. Lung deposition of inhaled tobramycin with eFlow rapid/LC Plus jet nebuliser in healthy and cystic fibrosis subjects. $J$ Cyst Fibros. 2011;10(1):9-14.

37. Goodman N, Morgan M, Nikander K, Hinch S, Coughlin S. Evaluation of patient-reported outcomes and quality of life with the I-neb AAD system in patients with chronic obstructive pulmonary disease. $J$ Aerosol Med Pulm Drug Deliv. 2010;23(suppl 1):S61-S70.

38. Anderson P. Use of Respimat ${ }^{\circledR}$ Soft Mist ${ }^{\mathrm{TM}}$ Inhaler in COPD patients. Int J Chron Obstruct Pulmon Dis. 2006;1(3):251-259.

39. Meyer KC. COPD 2013: an update on treatment and newly approved medications for pharmacists. J Am Pharm Assoc (2003). 2013;53(6): e219-e229. [quiz e230-1].

40. Loh CH, Donohue JF, Ohar JA. Review of drug safety and efficacy of arformoterol in chronic obstructive pulmonary disease. Expert Opin Drug Saf. 2015;14(3):463-472.

41. Donohue JF, Hanania NA, Make B, et al. One-year safety and efficacy study of arformoterol tartrate in patients with moderate to severe COPD. Chest. 2014;146(6):1531-1542.

42. King P. Role of arformoterol in the management of COPD. Int J Chron Obstruct Pulmon Dis. 2008;3(3):385-391.

43. Hanrahan JP, Hanania NA, Calhoun WJ, Sahn SA, Sciarappa K, Baumgartner RA. Effect of nebulized arformoterol on airway function in COPD: results from two randomized trials. COPD. 2008;5(1):25-34.

44. Baumgartner RA, Hanania NA, Calhoun WJ, Sahn SA, Sciarappa K, Hanrahan JP. Nebulized arformoterol in patients with COPD: a 12-week, multicenter, randomized, double-blind, double-dummy, placebo- and active-controlled trial. Clin Ther. 2007;29(2):261-278.

45. Tashkin DP, Donohue JF, Mahler DA, et al. Effects of arformoterol twice daily, tiotropium once daily, and their combination in patients with COPD. Respir Med. 2009;103(4):516-524.

46. Gross NJ, Nelson HS, Lapidus RJ, et al; Formoterol Study Group. Efficacy and safety of formoterol fumarate delivered by nebulization to COPD patients. Respir Med. 2008;102(2):189-197.

47. Kottakis J, Cioppa GD, Creemers J, et al. Faster onset of bronchodilation with formoterol than with salmeterol in patients with stable, moderate to severe COPD: results of a randomized, double-blind clinical study. Can Respir J. 2002;9(2):107-115.

48. Sutherland ER, Brazinsky S, Feldman G, McGinty J, Tomlinson L, Denis-Mize K. Nebulized formoterol effect on bronchodilation and satisfaction in COPD patients compared to QID ipratropium/albuterol MDI. Curr Med Res Opin. 2009;25(3):653-661.

49. Tashkin DP, Hanania NA, McGinty J, Denis-Mize K, Chaudry I. Nebulized formoterol provides added benefits to tiotropium treatment in chronic obstructive pulmonary disease. Adv Ther. 2009;26(11):1024-1034. 
50. Hanania NA, Boota A, Kerwin E, Tomlinson L, Denis-Mize K. Efficacy and safety of nebulized formoterol as add-on therapy in COPD patients receiving maintenance tiotropium bromide: results from a 6-week, randomized, placebo-controlled, clinical trial. Drugs. 2009;69(9):1205-1216.

51. Tashkin DP, Littner M, Andrews CP, Tomlinson L, Rinehart M, Denis-Mize K. Concomitant treatment with nebulized formoterol and tiotropium in subjects with COPD: a placebo-controlled trial. Respir Med. 2008;102(4):479-487.

52. Deeks ED. Olodaterol: a review of its use in chronic obstructive pulmonary disease. Drugs. 2015;75(6):665-673.

53. Boehringer Ingelheim. Newly published head-to-head data show stiolto $^{\mathrm{TM}}$ respimat $^{\circledR}$ (tiotropium bromide and olodaterol) improved lung function across range of measures [press release]. Boehringer Ingelheim; 2016 [February 9]. Available from: https://goo.gl/VpstiJ Accessed September 28, 2016.

54. Feldman GJ, Bernstein JA, Hamilton A, Nivens MC, Korducki L, LaForce C. The 24-h FEV1 time profile of olodaterol once daily via Respimat $^{\mathbb{R}}$ and formoterol twice daily via Aerolizer ${ }^{\circledR}$ in patients with GOLD 2-4 COPD: results from two 6-week crossover studies. Springerplus. 2014;3:419.

55. Keating GM. Tiotropium Respimat ${ }^{\circledR}$ soft mist inhaler: a review of its use in chronic obstructive pulmonary disease. Drugs. 2014;74(15):1801-1816.

56. Hochrainer D, Holz H, Kreher C, Scaffidi L, Spallek M, Wachtel H. Comparison of the aerosol velocity and spray duration of Respimat soft mist inhaler and pressurized metered dose inhalers. J Aerosol Med. 2005;18(3):273-282.

57. Iacono P, Velicitat P, Guemas E, Leclerc V, Thebault JJ. Improved delivery of ipratropium bromide using Respimat (a new soft mist inhaler) compared with a conventional metered dose inhaler: cumulative dose response study in patients with COPD. Respir Med. 2000;94(5):490-495.

58. Dahl R, Calverley PM, Anzueto A, et al. Safety and efficacy of tiotropium in patients switching from HandiHaler to Respimat in the TIOSPIR trial. BMJ Open. 2015;5(12):e009015.

59. Barr RG, Bourbeau J, Camargo CA, Ram FS. Inhaled tiotropium for stable chronic obstructive pulmonary disease. Cochrane Database Syst Rev. 2005;(2):CD002876.

60. ZuWallack R, Allen L, Hernandez G, Ting N, Abrahams R. Efficacy and safety of combining olodaterol Respimat ${ }^{\circledR}$ and tiotropium HandiHaler $^{\circledR}$ in patients with COPD: results of two randomized, double-blind, active-controlled studies. Int J Chron Obstruct Pulmon Dis. 2014;9:1133-1144.

61. Ferguson GT, Flezar M, Korn S, et al. Efficacy of tiotropium + olodaterol in patients with chronic obstructive pulmonary disease by initial disease severity and treatment intensity: a post hoc analysis. Adv Ther 2015;32(6):523-536.

62. Buhl R, Maltais F, Abrahams R, et al. Tiotropium and olodaterol fixeddose combination versus mono-components in COPD (GOLD 2-4). Eur Respir J. 2015;45(4):969-979.

63. Singh D, Ferguson GT, Bolitschek J, et al. Tiotropium + olodaterol shows clinically meaningful improvements in quality of life. Respir Med. 2015;109(10):1312-1319.

64. Datta D, Vitale A, Lahiri B, ZuWallack R. An evaluation of nebulized levalbuterol in stable COPD. Chest. 2003;124(3):844-849.

65. Nair S, Thomas E, Pearson SB, Henry MT. A randomized controlled trial to assess the optimal dose and effect of nebulized albuterol in acute exacerbations of COPD. Chest. 2005;128(1):48-54.

66. Borkowski J, Crader M. Nebulized albuterol versus levalbuterol in pediatric and adult patients: a review. Formulary. 2009;44:108-118.

67. Truitt T, Witko J, Halpern M. Levalbuterol compared to racemic albuterol: efficacy and outcomes in patients hospitalized with COPD or asthma. Chest. 2003;123(1):128-135.

68. Ipratropium Bromide. Ipratropium bromide solution [prescribing information]. FL: Cobalt Laboratories. Available from: https://ailymed.nlm. nih.gov/dailymed/getFile.cfm?setid=lf69f100f-c766-490f-9143-5e8e0 $\mathrm{c} 8 \mathrm{cb} 7 \mathrm{c} 9 \&$ type $=$ pdf\&name $=1 \mathrm{f} 69 \mathrm{f} 100 \mathrm{f}-\mathrm{c} 766-490 \mathrm{f}-9143-5 \mathrm{e} 8 \mathrm{e} 0 \mathrm{c} 8 \mathrm{cb} 7 \mathrm{c} 9$. Accessed March 13, 2016.
69. DuoNeb ${ }^{\circledR}$ (Ipratropium Bromide $0.5 \mathrm{mg} /$ Albuterol Sulfate $3.0 \mathrm{mg} *$ ) inhalation solution [prescribing information]. CA: Dey Pharma, L.P. Available from: http://www.accessdata.fda.gov/drugsatfda_docs/ label/2012/020950s037lbl.pdf. Accessed February 23, 2016.

70. The COMBIVENT Inhalation Solution Study Group. Routine nebulized ipratropium and albuterol together are better than either alone in COPD. The COMBIVENT Inhalation Solution Study Group. Chest. 1997;112(6): 1514-1521.

71. York JM, Smeeding J, Brook RA, Hoehler F, Klein GL. Exploratory economic evaluation of patients with COPD on a combination product versus individual components (ipratropium bromide and albuterol). $A d v$ Ther. 2007;24(4):757-771.

72. Combivent ${ }^{\mathbb{B}}$ Respimat $^{\mathbb{\circledR}}$ (ipratropium bromide and albuterol) inhalation spray [prescribing information] 1996. Available from: http://docs. boehringer-ingelheim.com/Prescribing\%20Information/PIs/Combivent\%20Respimat/CMVTRSPT.pdf. Accessed May 24, 2016.

73. Leaker BR, Barnes PJ, Jones CR, Tutuncu A, Singh D. Efficacy and safety of nebulized glycopyrrolate for administration using a high efficiency nebulizer in patients with chronic obstructive pulmonary disease. Br J Clin Pharmacol. 2015;79(3):492-500.

74. Fogarty C, Dunn K, Singh D, Tutuncu A, Kerwin E. Cardiovascular safety of nebulized glycopyrrolate (SUN-101) compared with tiotropium, ipratropium and placebo in patients with COPD. Clin Res. 2013;2(3):4

75. Sunovion Respiratory Development Inc. Randomized, double-blind, placebo-controlled, parallel-group, multicenter, efficacy and safety trial of 12 weeks of treatment with nebulized SUN-101 in patients with COPD: Golden-3 (glycopyrrolate for obstructive lung disease via electronic nebulizer). Available from: https://clinicaltrials.gov/ct2/ show/NCT02347761?term=NLM identifier\&rank=1. NCT02347761. NLM identifier: NCT02347761. Accessed March 13, 2016.

76. Sunovion Respiratory Development Inc. A randomized, double-blind, placebo-controlled, parallel-group, multicenter, efficacy and safety trial of 12 weeks of treatment with nebulized SUN-101 in patients with COPD: Golden-4 (glycopyrrolate for obstructive lung disease via electronic nebulizer). Available from: https://clinicaltrials.gov/ct2/ show/NCT02347774?term=NCT02347774\&rank=1. NLM identifier: NCT02347774. Accessed March 13, 2016.

77. Sunovion Respiratory Development Inc. A randomized, open-label, active-controlled, parallel-group, multicenter, long-term safety trial of treatment with nebulized SUN-101 in patients with COPD: Golden-5 (glycopyrrolate for obstructive lung disease via electronic nebulizer). Available from: https:/clinicaltrials.gov/ct2/show/NCT02276222?ter $\mathrm{m}=$ NCT02276222\&rank=1. NLM identifier: NCT02276222. Accessed March 13, 2016.

78. Gross N. The COPD pipeline, XXVIII. J COPD Found. 2015;2(3): 259-263.

79. Pulido-Rios MT, McNamara A, Obedencio GP, et al. In vivo pharmacological characterization of TD-4208, a novel lung-selective inhaled muscarinic antagonist with sustained bronchoprotective effect in experimental animal models. J Pharmacol Exp Ther. 2013;346(2): $241-250$.

80. Lo A, Nicholls AJ, Haumann B, Moran EJ, Bourdet DL. A population PK model of once-daily TD-4208, a nebulized long-acting muscarinic antagonist (LAMA) in patients with chronic obstructive pulmonary disease (COPD). Am J Respir Crit Care Med. 2015;191:A5764. [Abstract].

81. Nicholls AJ, Barnes C, Yates W, Moran EJ, Singh D. A randomized, crossover, 7-day study of once-daily TD-4208, a long-acting muscarinic antagonist, in subjects with COPD. Am J Respir Crit Care Med. 2014;189:A6003. [Abstract].

82. Haumann BK, Nicholls AJ, Barnes C, Bourdet DL, Moran EJ. Doseranging study of once-daily TD-4208, an inhaled long-acting muscarinic antagonist (LAMA) in patients with chronic obstructive pulmonary disease (COPD). Am J Respir Crit Care Med. 2015;191:A5750. [Abstract]. 
83. Theravance Biopharma R \& D, Inc. A phase 3, 12-week, randomized, double-blind placebo-controlled parallel group study of nebulized TD-4208 in subjects with chronic obstructive pulmonary disease. Available from: https://goo.gl/ab2VxL?term=NLM identifier\&rank=NCT02459080. NLM identifier: NCT02459080. Accessed March 13, 2016.

84. Theravance Biopharma R \& D, Inc. A phase 3, 12-week, randomized, double-blind placebo-controlled parallel group study of nebulized TD-4208 in subjects with chronic obstructive pulmonary disease. Available from: https:/goo.gl/fPyjfM?term=NLM identifier\&rank=NCT02512510. NLM identifier: NCT02512510. Accessed March 13, 2016.

85. Theravance Biopharma R \& D, Inc. A phase 3, 52-week, randomized, active-controlled parallel group study to evaluate the safety and tolerability of nebulized TD-4208 in subjects with chronic obstructive pulmonary disease. Available from: https://goo.gl/83EjwX?term=NLM identifier\&rank=NCT02518139. NLM identifier: NCT02518139. Accessed March 13, 2016.

86. Tashkin DP, Klein GL, Colman SS, Zayed H, Schonfeld WH. Comparing COPD treatment: Nebulizer, metered dose inhaler, and concomitant therapy. Am J Med. 2007;120(5):435-441.

87. Brovana. Brovana medical guide and prescribing information; 2006. Available from: http://www.brovana.com/brovana-approved-labelingtext.pdf. Accessed May 24, 2016.

88. The Global Initiative for Chronic Obstructive Lung Disease. The 2016 Global Strategy for Diagnosis, Management, and Prevention of COPD. Available from: http://goo.gl/ItQL3a. Accessed March 3, 2016.

89. Tashkin DP, Ferguson GT. Combination bronchodilator therapy in the management of chronic obstructive pulmonary disease. Respir Res. 2013;14:49.

90. Cazzola M, Segreti A, Matera MG. New developments in the combination treatment of COPD: focus on umeclidinium/vilanterol. Drug Des Devel Ther. 2013;7:1201-1208.

91. Adi H, Young PM, Traini D. Co-deposition of a triple therapy drug formulation for the treatment of chronic obstructive pulmonary disease using solution-based pressurised metered dose inhalers. J Pharm Pharmacol. 2012;64(9):1245-1253.

92. Lechuga-Ballesteros D, Noga B, Vehring R, Cummings RH, Dwivedi SK. Novel cosuspension metered-dose inhalers for the combination therapy of chronic obstructive pulmonary disease and asthma. Future Med Chem. 2011;3(13):1703-1718.

93. Bevespi Aerosphere ${ }^{\mathrm{TM}}$ (glycopyrrolate and formoterol fumarate) inhalation aerosol, for oral inhalation use [prescribing information] 2016. Holmes Chapel: Aventis Pharma LTD. Available from: http://www. accessdata.fda.gov/drugsatfda_docs/label/2016/208294s0001bl.pdf. Accessed May 24, 2016.
94. Barnes PJ. Triple inhalers for obstructive airways disease: will they be useful? Expert Rev Respir Med. 2011;5(3):297-300.

95. Lipworth B. Triple inhaler therapy for COPD. Thorax. 2015; 70(10):991.

96. Trivedi RK, Chendake DS, Patel MC. A rapid, stability-indicating RP-HPLC method for the simultaneous determination of formoterol fumarate, tiotropium bromide, and ciclesonide in a pulmonary drug product. Sci Pharm. 2012;80(3):591-603.

97. Vestbo J, Hurd SS, Agusti AG, et al. Global strategy for the diagnosis, management, and prevention of chronic obstructive pulmonary disease: GOLD executive summary. Am J Respir Crit Care Med. 2013;187(4):347-365.

98. Laube BL, Janssens HM, Jongh FH, Devadason SG, Dhand R, Diot P. What the pulmonary specialist should know about the new inhalation therapies. Eur Respir J. 2011;37(6):1308-1331.

99. Gross NJ, Donohue JF. Nebulized formoterol: a review of clinical efficacy and safety in COPD. Int J Chron Obstruct Pulmon Dis. 2010;5: 223-232.

100. Ferguson GT, Feldman GJ, Hofbauer P, et al. Efficacy and safety of olodaterol once daily delivered via Respimat ${ }^{\mathbb{8}}$ in patients with GOLD 2-4 COPD: results from two replicate 48-week studies. Int J Chron Obstruct Pulmon Dis. 2014;9:629-645.

101. van Noord JA, Cornelissen PJ, Aumann JL, Platz J, Mueller A, Fogarty C. The efficacy of tiotropium administered via Respimat soft mist inhaler or HandiHaler in COPD patients. Respir Med. 2009;103(1): $22-29$.

102. Accuneb ${ }^{\circledR}$ (albuterol sulfate) inhalation solution [prescribing information]. Available from: http://dailymed.nlm.nih.gov/dailymed/getFile. $\mathrm{cfm}$ ?setid=fa5ebedb-069c-4a1e-9a25-b6fa957e6c 2 b \& type $=$ pdf $\&$ name $=$ fa5ebedb-069c-4a1e-9a25-b6fa957e6c2b. Accessed March 13, 2016.

103. Xopenex ${ }^{\circledR}$ (levalbuterol $\mathrm{HCl}$ ) inhalation solution [prescribing information]. Available from: https://dailymed.nlm.nih.gov/dailymed/ archives/fdaDrugInfo.cfm?archiveid=20083. Accessed March 13, 2016.

104. Theravance Biopharma. Theravance Biopharma announces positive top-line results from phase $2 \mathrm{~b}$ dose-ranging study of its investigational LAMA, TD-4208, for the treatment of COPD [press release]. Theravance Biopharma; 2014 [September 8]. Available from: https://goo. gl/fhudYX. Accessed September 28, 2016.

105. Kesser KC, Geller DE. New aerosol delivery devices for cystic fibrosis. Respir Care. 2009;54(6):754-767.
International Journal of COPD

\section{Publish your work in this journal}

The International Journal of COPD is an international, peer-reviewed journal of therapeutics and pharmacology focusing on concise rapid reporting of clinical studies and reviews in COPD. Special focus is given to the pathophysiological processes underlying the disease, intervention programs, patient focused education, and self management protocols.

\section{Dovepress}

This journal is indexed on PubMed Central, MedLine and CAS. The manuscript management system is completely online and includes a very quick and fair peer-review system, which is all easy to use. Visit http://www.dovepress.com/testimonials.php to read real quotes from published authors. 